Kocaeli Journal of Science and Engineering

\title{
Analysis of Beam Vibrations on Partial Elastic Foundation Using Adomian Decomposition Method
}

\author{
Cebrail ÇíNÇĩ ${ }^{1, *}$ (D), Safa Bozkurt COŞKUN² (i) \\ ${ }^{1}$ Department of Civil Engineering, Kocaeli University, Kocaeli, 41310, Turkey, ORCID: 0000-0002-5106-8561 \\ ${ }^{2}$ Department of Civil Engineering, Kocaeli University, Kocaeli, 41310, Turkey, ORCID: 0000-0002-1962-7722
}

Article Info

Research paper

Received : December 02, 2018

Accepted : August 28, 2019

Keywords

Adomian Decomposition Method

Euler-Bernoulli Beam

Free Vibration

Partial Elastic Foundation

\section{Introduction}

Beams on elastic foundations have been extensively investigated due to its importance in geotechnical and structural engineering. However, the studies on beams partially supported on elastic foundations are relatively limited. Doyle and Pavlovic are determined natural vibration frequencies of beams partially and fully supported on elastic foundations [1]. Eisenberger et al. developed a generalized solution for the dynamic analysis of continuous beams on elastic foundations [2]. Laura and Cortinez used Rayleigh-Schimidt approach to obtain natural vibration frequencies of beams on partial Winkler foundations [3]. Kukla considered lateral free vibration of a beam on steplike varying Winkler foundation [4]. Thambiratnam and Zhuge developed a finite element formulation for dynamic analysis of beams on elastic foundations [5]. Motaghian et al. produced exact solutions to beams vibrating on partial elastic foundations [6]. Cazzani studied the dynamics of beams on partial elastic foundations [7]. Coşkun et al. and Çinçin used ADM for free vibration of analysis of a cantilever beam partially supported on Winkler foundation

\footnotetext{
* Corresponding Author: sb.coskun@kocaeli.edu.tr
}

\section{[8-9].}

ADM is a powerful analytical approximation technique for solving deterministic/stochastic, ordinary/partial, linear/nonlinear differential equations [10]. Wazwaz compared ADM and Taylor series method for the solution nonlinear differential equations [11]. Mao and Pietrzko studied the free vibration of stepped and tapered beams using ADM [12, 13]. Coşkun et al. described the application of various analytical approximation techniques including ADM to beam vibration problems [14]. Coşkun et al. proposed an ADM formulation for free vibration analysis of a nonuniform Euler beam on elastic foundation [15].

In this study, a uniform Euler beam partially supported on Winkler foundation is considered. ADM is used for the analyses and various end conditions for the beam is implemented to observe the effect of boundary conditions on the solution.

\section{Beam on Partial Elastic Foundation}

A uniform Euler beam partially supported on elastic foundation is shown below in Figure 1. 


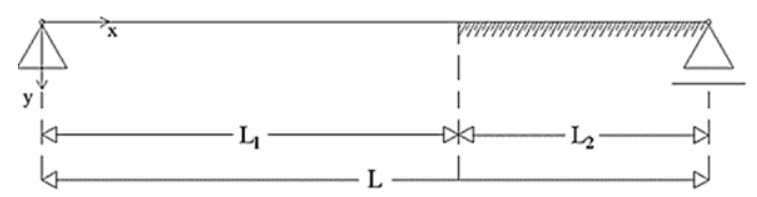

Figure 1. Beam on partial elastic foundation.

The vibration of the beam shown in Figure 1 is governed by following equations.

$\frac{\partial^{2}}{\partial x^{2}}\left(\operatorname{EI}(x) \frac{\partial^{2} y}{\partial x^{2}}\right)+\rho A \frac{\partial^{2}}{\partial t^{2}}+k y=0$

$\frac{\partial^{2}}{\partial x^{2}}\left(\operatorname{EI}(x) \frac{\partial^{2} y}{\partial x^{2}}\right)+\rho A \frac{\partial^{2}}{\partial t^{2}}=0$

Eq. (1) governs the vibration of the part of the beam supported by elastic foundation while Eq. (2) governs the vibration of the beam only. In Eqs.(1-2) $y(x, t)$ is the displacement, $\mathrm{k}$ is foundation modulus, $\mathrm{EI}(\mathrm{x})$ is flexural rigidity, $\rho$ is density and $A$ is cross-sectional area. If the beam is uniform Eqs.(1-2) become:

$\mathrm{EI} \frac{\partial^{4} \mathrm{y}}{\partial \mathrm{x}^{4}}+\rho \mathrm{A} \frac{\partial^{2} \mathrm{y}}{\partial \mathrm{t}^{2}}+\mathrm{ky}=0$

$\mathrm{EI} \frac{\partial^{4} \mathrm{y}}{\partial \mathrm{x}^{4}}+\rho \mathrm{A} \frac{\partial^{2} \mathrm{y}}{\partial \mathrm{t}^{2}}=0$

By the use of separation of variables technique, the displacement can be rearranged as follows:

$y(x, t)=w(x) q(t)$

Inserting Eq. (5) into Eqs. (3-4) one can obtain

$\mathrm{w}^{\mathrm{iv}}-\beta^{4} \mathrm{w}=0$

$\ddot{\mathrm{q}}+\omega^{2} \mathrm{q}=0$

Modal shapes are obtained via Eq. (6). The term $\beta^{4}$ in are different for the beam on elastic foundation (Eq.(8)) and the beam which is not supported by the foundation (Eq. (9)).

$\beta^{4}=\frac{\rho \mathrm{A} \omega^{2}-\mathrm{k}}{\mathrm{EI}}$

$\beta^{4}=\frac{\rho \mathrm{A} \omega^{2}}{\mathrm{EI}}$
The boundary conditions for the beam are given in Eqs. (10-12) corresponding to differend support types as follows.

- Simple support $(\mathrm{y}=0)$ :

$\mathrm{EI} \frac{\mathrm{d}^{2} \mathrm{y}}{\mathrm{dx}^{2}}=0$

- Fixed support $(\mathrm{y}=0)$ :

$\frac{\mathrm{dy}}{\mathrm{dx}}=0$

- Free end:

EI $\frac{d^{2} y}{d x^{2}}=0 \quad \frac{d}{d x}\left(\right.$ EI $\left.\frac{d^{2} y}{d x^{2}}\right)=0$

Continuity $\mathrm{x}=\mathrm{L}_{1}$ in Figure 1 should be considered for displacement, slope, moment and shear force as internal boundary conditions for the problem. Next, ADM for the current problem is introduced and the formulation for the analysis is presented.

\section{ADM for Free Vibration}

In ADM a general form of the differential equation is considered:

$\mathrm{Lu}+\mathrm{Ru}+\mathrm{Nu}=\mathrm{g}(\mathrm{x})$

where $u(x)$ is the unknown solution, $g(x)$ is the source term, $\mathrm{L}$ is the linear operator, $\mathrm{N}$ is the nonlinear operator and $\mathrm{R}$ is the operator for remainder terms. The solution to Eq.(13) is:

$u(x)=f(x)-L^{-1}(R u)-L^{-1}(N u)$

In Eq. (14) $\mathrm{L}^{-1}$ is the inverse linear operator and $f(\mathrm{x})=\mathrm{L}^{-1}(\mathrm{~g}(\mathrm{x}))$. The solution is provided with an infinite series as follows:

$\mathrm{u}(\mathrm{x})=\sum_{\mathrm{n}=0}^{\infty} \mathrm{u}_{\mathrm{n}}(\mathrm{x})$

The nonlinear term $\mathrm{Nu}$ is represented by so-called Adomian polynomials given below:

$\mathrm{Nu}=\sum_{\mathrm{n}=0}^{\infty} \mathrm{A}_{\mathrm{n}}\left(\mathrm{u}_{0}, \mathrm{u}_{1}, \ldots, \mathrm{u}_{\mathrm{n}}\right)$ 
Adomian polynomials $A_{n}$ is defined by the following term:

$\mathrm{A}_{\mathrm{n}}=\frac{1}{\mathrm{n} !} \frac{\mathrm{d}^{\mathrm{n}}}{\mathrm{d} \lambda^{\mathrm{n}}} \mathrm{N}\left(\sum_{\mathrm{n}=0}^{\infty} \lambda^{\mathrm{k}} \mathrm{u}_{\mathrm{k}}\right)$

The reader may refer to for further details. The method leads to a successive approximation process as follows [10]:

$u_{0}(x)=f(x)$

$u_{n}(x)=-L^{-1}\left(R u_{n-1}-A_{n-1}\right), n>0$

The solution is constructed by adding successive approximations according to Eq. (15). An $\mathrm{N}^{\text {th }}$ order solution includes the terms up to $\mathrm{u}_{\mathrm{N}}$ as given below:

$\mathrm{u}(\mathrm{x})=\sum_{\mathrm{n}=0}^{\mathrm{N}} \mathrm{u}_{\mathrm{n}}(\mathrm{x})$

For the problem the terms in ADM formulation are:

$L_{y}=\frac{d^{4} y}{d x^{4}}, \quad R_{y}=-\beta^{4} y, \quad N_{y}=0, \quad g(x)=0$

An initial approximation based on Eq. (18) may be obtained as

$y(x)=A+B x+C x^{2}+D x^{3}$

where $\mathrm{A}=\mathrm{y}(0), \mathrm{B}=\mathrm{y}^{\prime}(0), \mathrm{C}=\mathrm{y}^{\prime \prime}(0) / 2$ and $\mathrm{y}^{\prime \prime \prime}(0) / 6$. Successive approximations for an $\mathrm{N}^{\text {th }}$ order solution may be constructed according to Eq. (19).

$\mathrm{y}_{\mathrm{n}}(\mathrm{x})=\mathrm{L}^{-1}\left[\beta^{4} \mathrm{y}_{\mathrm{n}-1}\right], \mathrm{n}>0$

After obtaining an $\mathrm{N}^{\text {th }}$ order approximation, four end support conditions and four internal continuity conditions are applied to it. Then eight equations in eight unknowns are produced that can be represented in the following matrix form.

$[\mathrm{M}]_{8 \times 8}\{\propto\}_{8 \times 1}=\{0\}_{8 \times 1}$

where $[\mathrm{M}]$ is function of $\beta$ and the unknown vector $\{\alpha\}$ include unknown coefficients in the initial approximation. The nontrivial solution to the problem may be obtained by calculating the determinant of coefficient matrix and equating zero that lead to free vibration frequencies of the beam considered.

\section{Case Study}

Kukla considered the cantilever beam on partial elastic foundation depicted in Figure 2. In the problem $\mathrm{EI}=408.4 \mathrm{kNm}^{2}, \rho \mathrm{A}=30.394 \mathrm{Ns}^{2} / \mathrm{m}^{2}, \mathrm{~L}=4.0 \mathrm{~m}$ were assumed and nondimensional partial elastic foundation length is described as $\mu=\mathrm{L}_{1} / \mathrm{L}_{2}$ [4].

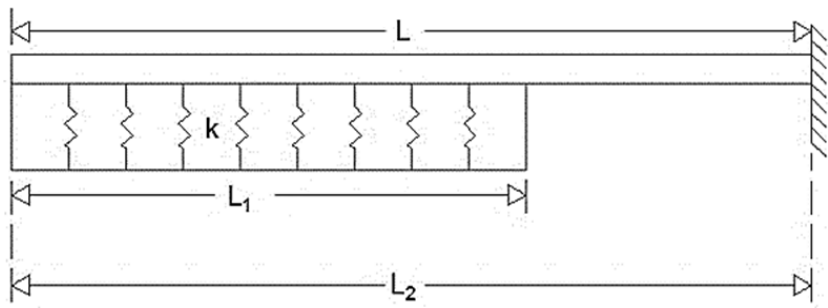

Figure 2. Cantilever beam on partial elastic foundation [4].

Same problem is solved using ADM and first four nondimensional vibration frequencies are compared in between Figures (3-6).

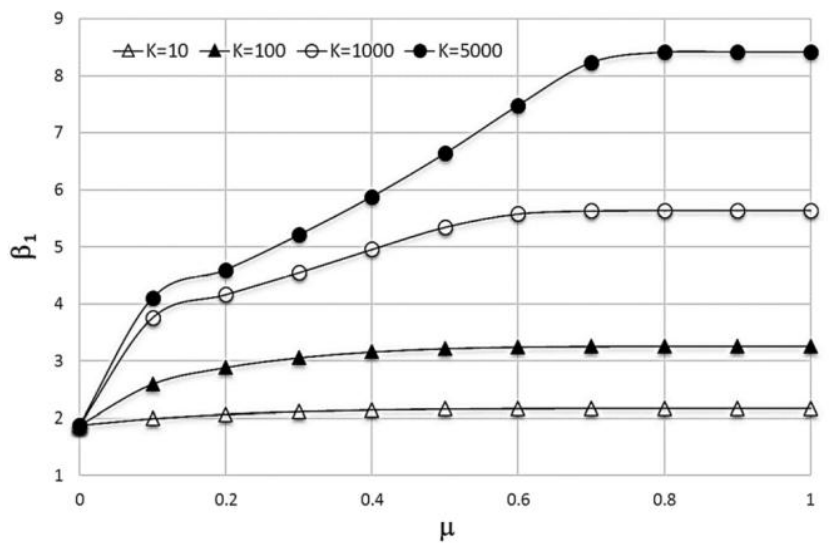

Figure 3. Comparison for the first nondimensional frequencies (Solid lines [4], Symbols - ADM Solution).

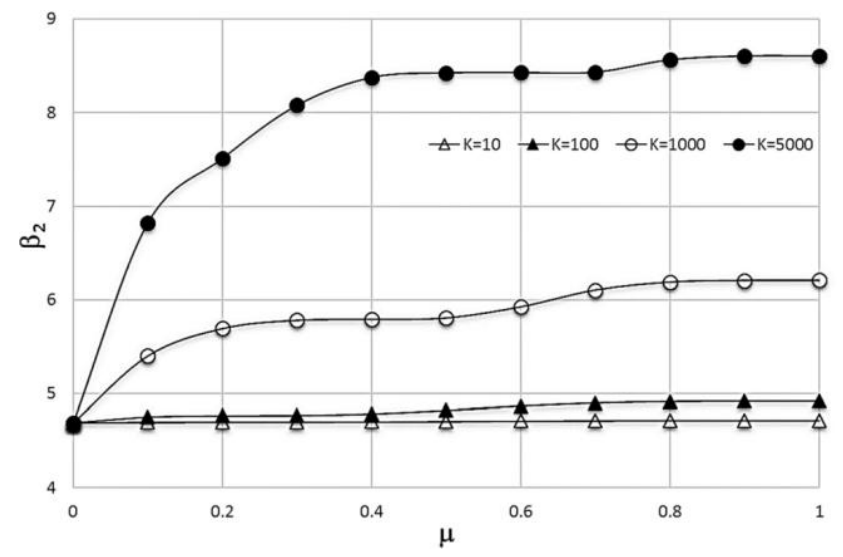

Figure 4. Comparison for the second nondimensional frequencies (Solid lines [4], Symbols - ADM Solution).

In this paper, Direct Drive PMSG Wind Turbine energy conversion principle scheme is shown in Figure 1. 


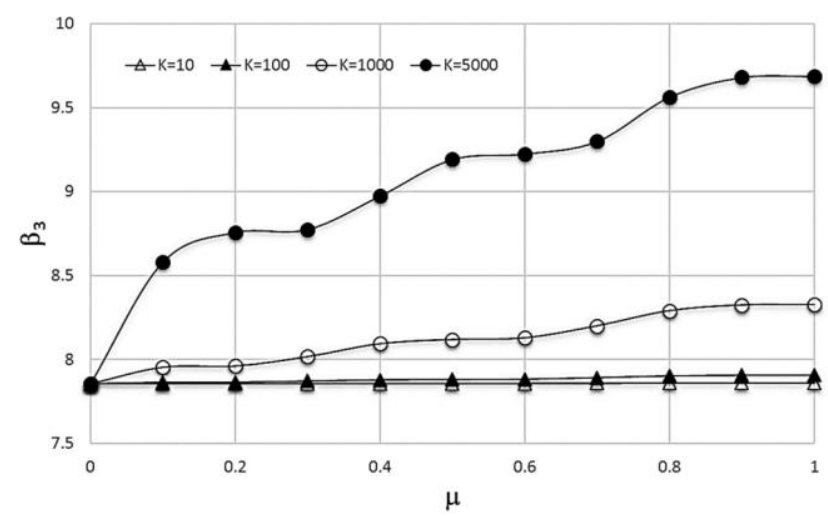

Figure 5. Comparison for the third nondimensional frequencies (Solid lines [4], Symbols - ADM Solution).

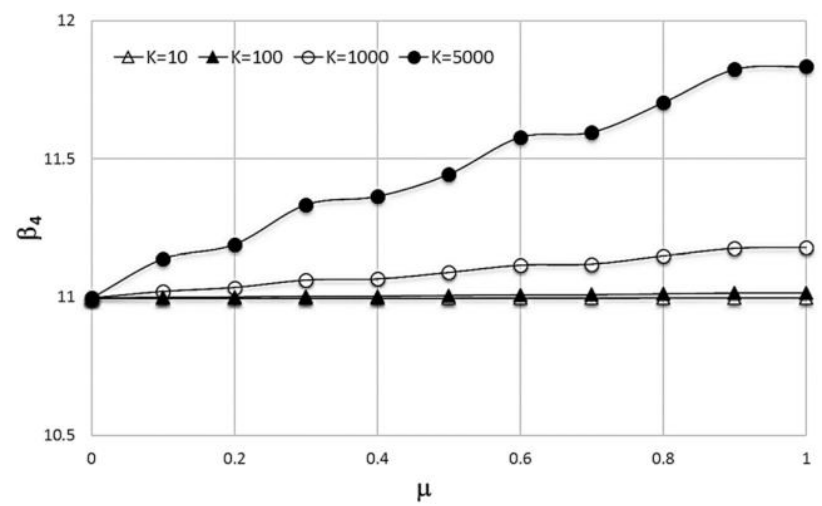

Figure 6. Comparison for the fourth nondimensional frequencies (Solid lines [4], Symbols - ADM Solution).

As seen in Figures (3-6), there is a perfect agreement among the ADM solutions and the results by Kukla [4]. Since Kukla only considered only a cantilever, the results will be extended according to different support conditions. For this purpose, some abbreviations are introduced for different types of supports. These are; $\mathrm{C}$ for clamped support, $\mathrm{S}$ for simple support and $\mathrm{F}$ for free end. Hence, the beam analyzed by Kukla may be introduced as CF beam and SS, CS and CC beams are also included in ADM analyses to extend the previous analysis due to these different boundary conditions.

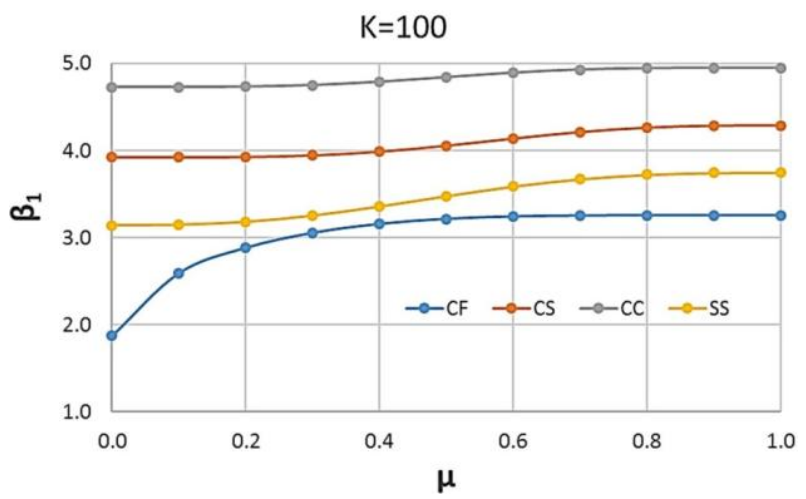

Figure 7. Comparison of the first nondimensional frequencies for different beams $(K=100)$.
Below, first three nondimensional vibration frequencies of different beams are compared for different foundation coefficient. Figures (7-9) depict the results for $\mathrm{K}=100$ and Figures (10-12) depict the results for $\mathrm{K}=$ 5000 .

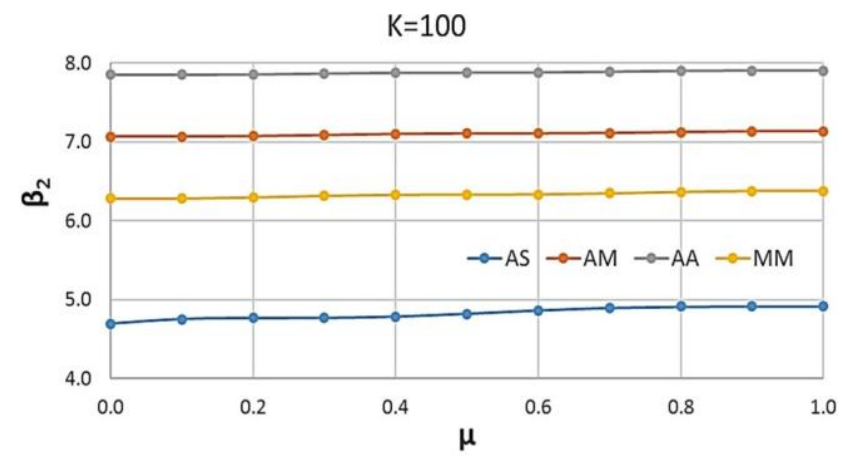

Figure 8. Comparison of the second nondimensional frequencies for different beams $(\mathrm{K}=100)$.

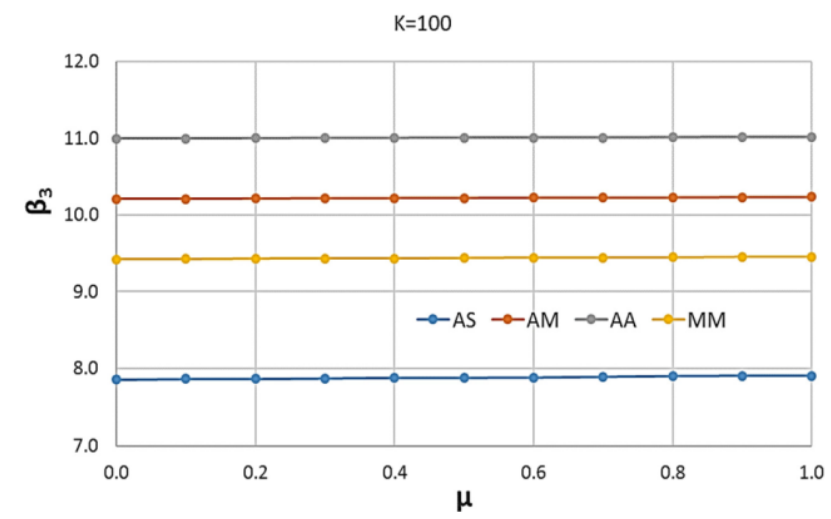

Figure 9. Comparison of the third nondimensional frequencies for different beams $(K=100)$.

$K=5000$

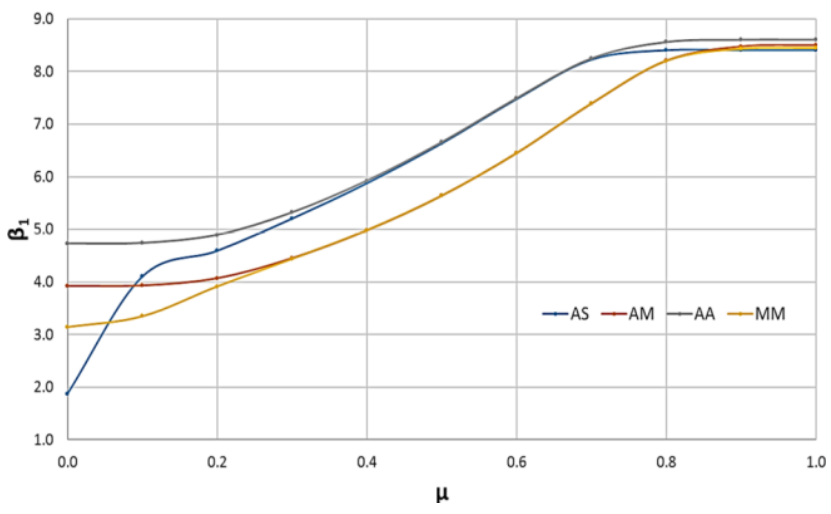

Figure 10. Comparison of the first nondimensional frequencies for different beams $(K=5000)$.

In Figures (7-9), it may be observed the vibration frequencies from small to large values are for $\mathrm{CF}, \mathrm{MM}$, $\mathrm{CS}$ and $\mathrm{CC}$ beams respectively for all three frequencies. However, in Figures (10-11), the vibration frequencies of $\mathrm{CF}$ beam is highly influenced by large foundation modulus for the interval $0.1<\mu<0.4$. 


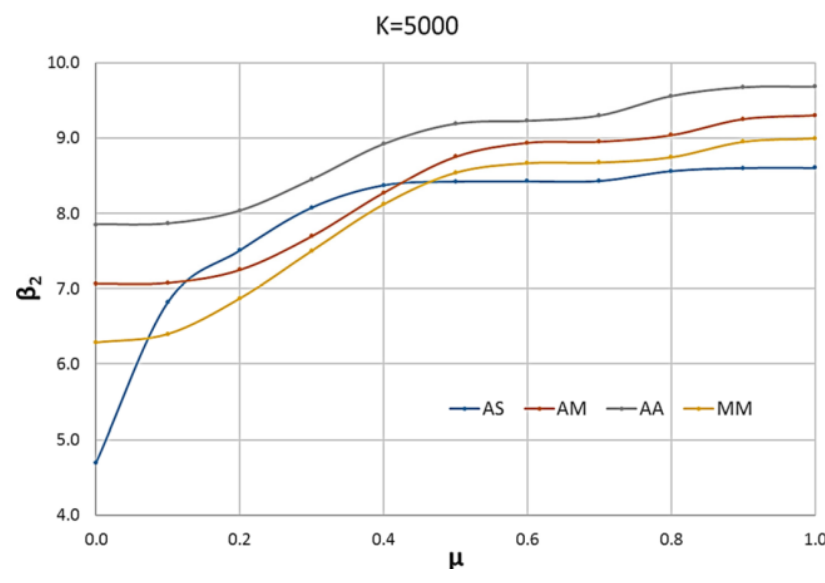

Figure 11. Comparison of the second nondimensional frequencies for different beams $(K=5000)$.

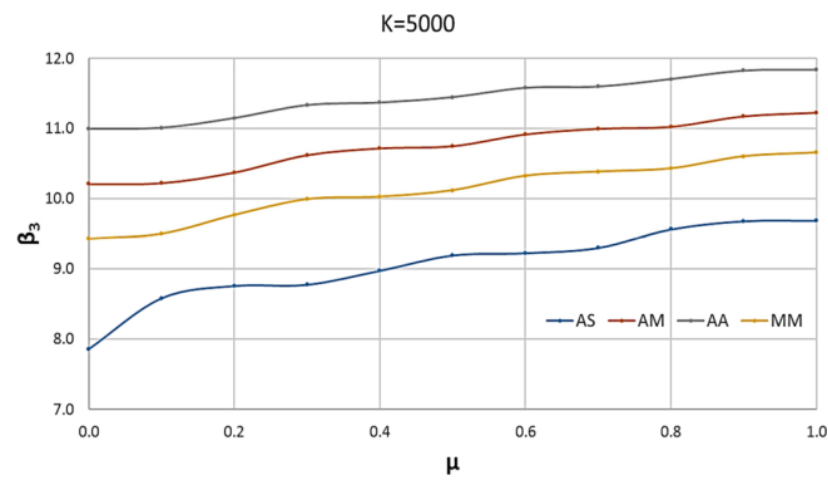

Figure 12. Comparison of the third nondimensional frequencies for different beams $(K=5000)$.

\section{Conclusion}

In this study, dynamic analysis of beams partially supported by elastic foundation is conducted by using ADM. ADM is an analytical approximation technique and provides analytical expressions as solution instead of discrete numerical values which is a great advantage and superiority of the technique. The problem is defined in two regions, while in one region beam is vibrating on elastic foundation, it is vibrating alone in neighboring region. Even with uniform properties it is not an easy task to produce characteristic values for such a beam. However, it is very easy to formulate and analyze such a problem using ADM. In the paper, a cantilever beam is considered first and ADM results are compared with analytical solutions. Then the solution is extended easily for different support conditions, which is not the same for analytical solution. The study is a clear representation of how ADM can be successfully used in analyzing beam vibration for beams on partial elastic foundation.

\section{References}

[1] Doyle P. F., Pavlovic M. N., 1982. Vibration of
Beams on Partial Elastic Foundations. Earthquake Engineering and Structural Dynamics, 10(5), 663674.

[2] Eisenberger M., Yankelevsky D. Z., Adin M. A., 1985. Vibrations of Beams Fully or Partially Supported on Elastic Foundations. Earthquake Engineering and Structural Dynamics, 13(5), 651660.

[3] Laura P. A. A., Cortinez V. H., 1987. Vibrating Beam Partially Embedded in Winkler-Type Foundation. Journal of Engineering Mechanics, 113(1), 143-147.

[4] Kukla S., 1991. Free Vibration of a Beam Supported on a Stepped Elastic Foundation. Journal of Sound and Vibration, 149(2), 259-265.

[5] Thambiratnam D., Zhuge Y., 1996. Free Vibration Analysis of Beams on Elastic Foundation. Computers \& Structures, 60(6), 971-980.

[6] Motaghian S. E., Mofida M., Alanjari P., 2011. Exact Solution to Free Vibration of Beams Partially Supported by an Elastic Foundation. Scientia Iranica, 18(4), 861-866.

[7] Cazzani A., 2013. On the Dynamics of a Beam Partially Supported by an Elastic Foundation: An Exact Solution Set. International Journal of Structural Stability and Dynamics, doi: 10.1142/S0219455413500454.

[8] Coşkun S. B., Mutman U., Çinçin C., 2015. Free Vibration Analysis of A Beam Partially Supported on Elastic Foundation Using Adomian Decomposition Method. 5th International Earthquake Symposium, Kocaeli, Turkey, 10-12 June.

[9] Çinçin C., 2018. Analysis of Vibration A Beam Partially Supported on Elastic Foundation Using Adomian Decomposition Method. M. Sc. Thesis, Kocaeli University, Kocaeli.

[10] Adomian G., 1994. Solving Frontier Problems of Physics: The Decomposition Method, Kluwer Academic Publishers, Boston.

[11] Wazwaz A. M., 1998. A Comparison between Adomian Decomposition Method and Taylor Series Method in the Series Solutions. Applied Mathematics and Computation, 97(1), 37-44.

[12] Mao Q., Pietrzko S., 2010. Free Vibration Analysis of Stepped Beams by Using Adomian Decomposition Method. Applied Mathematics and Computation, 217(7), 3429-3441.

[13] Mao Q., Pietrzko S., 2012. Free Vibration Analysis of a Type of Tapered Beams by Using Adomian 
Decomposition Method. Applied Mathematics and Computation, 219(6), 3264-3271.

[14] Coşkun S. B., Atay M. T., Öztürk B., 2011. Transverse Vibration Analysis of Euler-Bernoulli Beams Using Analytical Approximate Techniques, Advances in Vibration Analysis Research, ed: Ebrahimi F., Intech Press, pp. 1-22, doi: 10.5772/639.

[15] Coşkun S. B., Öztürk B., Mutman U., 2014. Adomian Decomposition Method for Vibration of Nonuniform Euler Beams on Elastic Foundation, Proceedings of the 9th International Conference on Structural Dynamics (EURODYN 2014), 1935-1940. 